ISSN: 2146-3042

DOI: $10.25095 /$ mufad.607150

\title{
Maliyet Fonksiyonun Belirlenmesinde Yapay Sinir A Modellerinin Kullanımı
}

\author{
Bülent YILMAZ ${ }^{* *}$
}

\section{ÖZET}

Maliyet ve iş hacmi arasındaki ilişkilerin ortaya konmasında muhasebede kullanılan yöntemlere yardımcı olarak mühendislik ve istatistiki tekniklerden faydalanılmaktadır. Giderlerin sinıflandirlarak toplam maliyet fonksiyonun belirlenmesinde kullanılan her bir yöntem diğer yöntemin eksikliğini gidererek daha üstün bir yöntem haline getirmektedir. Bu yöntemler genel olarak matematik ve istatistiki teknikler ismi altında toplanmaktadır. Yapay sinir ağı modellerinin üstün ve eksik yönleri ortaya konarak özellikle matematik ve istatistiki diğer tekniklerin yetersiz kaldiğı koşullarda maliyet fonksiyonun belirlenmesinde yapay sinir ağlarının kullanılabileceği öngörülmektedir. Bu çalışma da m2 başına bir evin toplam maliyet fonksiyonun belirlenmesinde literatürde kullanılan grafik tekniği, en düşük en yüksek hacimler tekniği, çifte ortalama tekniği ve en küçük kareler tekniğine alternatif olarak yapay sinir ağı modelleri ile maliyet fonksiyonu tahmin edilmeye çalışlmış ve elde edilen sonuçlar diğer yöntemlerle mukayese edilmiştir. Sonuçta bir evin m2 başına birim maliyetine etki eden faktör ile kurulan maliyet fonksiyonunda özellikle en küçük kareler tekniği ve yapay sinir ağı modellerinin yaklaşık benzer sonuçlar elde ettikleri tespit edilmiştir.

Anahtar Kelimeler: Maliyet Fonksiyonu, Yapay Sinir Ağları, Matematik ve İstatistiki Teknikler.

JEL Sinıflandirmasi: M40, C45, C50, G17.

\section{Use of Artificial Neural Network Modelsfor Determination of Total Cost Function}

ABSTRACT

Engineering and statistical techniques are used by assisting the methods used in accounting to determine the relations between costand volume. Each method used in determining the total costfunction by classifying the expenses makes it a superior method by eliminating the lack of other method. These methods are collected under the name of mathematics and statistical techniques in general. It is predicted that artificial neural networks can be used in determining the cost function in conditions where the mathematica land statistical other techniques are insufficient. Inthisstudy, graphic technique used in the literature to determine the total cost function of one house per m2, lowest maximum volume technique, double average technique and alternative function of artificial neural network models as an alternative to least squares technique were tried to be estimated and compared with other methods. It was. As a result, it was determined that the least squares technique and artificial neural network models had similar results in the cost functione stablished by the factor effecting the unit cost per $m 2$ of a house.

KeyWords: CostFunction, Artificial Neural Networks, Mathematics and Statistical Techniques.

Jel Classification: M40, C45, C50, G17.

Makale Gönderim Tarihi: 01.06.2019

Makale Kabul Tarihi: 01.08.2019

Makale Türü: Araştırma Makalesi

\footnotetext{
* Bu çalışma, 1-4 Mayıs 2019 tarihlerinde Bursa'da düzenlenen V. Uluslararası Muhasebe ve Finans Sempozyumu'nda özet bildiri olarak sunulmuştur.

***Asist. Prof. Milli Savunma Üniversitesi, Türkiye, byilmaz@kho.edu.tr, ORCID:0000-0003-1114-2365
} 


\section{GíRİş}

İşletmelerin süreklilik ilkesi çerçevesinde ticari hayatlarını sürdürülebilir kılabilmeleri için yaratmaya çalıştıkları en önemli unsur, bir üretim ya da hizmetin meydana getirilmesi sonucunda oluşan gelirlerinin ve giderlerinin farkının meydana getirdiği kâr olgusudur. İşletmeler finansal performanslarını artırabilmek maksadıyla değişik finansal performans göstergelerinden yaralanarak bazı politika ve stratejik yöntemler uygulayabilmektedir. Burada unutulmaması gereken en önemli husus kârın kesişim olarak yer aldığı ve kârın oluşmasındaetken olan bileşenlerin iyi analiz edilmesi ve karar verici durumundaki yöneticilerin analiz sonuçlarına göre doğru yol haritalarını belirleyebilmeleridir.

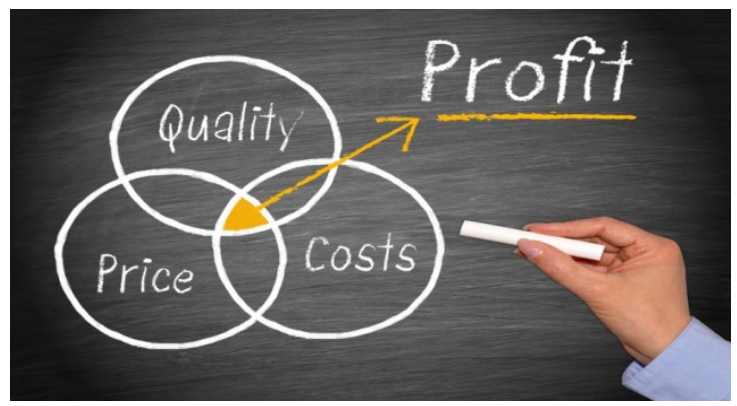

Şekil 1. Kârı Oluşturan Unsurlar

Kaliteli üretim veya hizmet, iyi analizler sonucu tespit edilmiş bir fiyat ve tabi ki maliyet, kârı ortak noktalarına alarak oluşan unsurlardır. Sınırların ortadan kalktığı ve artık yararından çok zararının konuşulduğu ve ayrı bir çalışma konusu olarak karşımıza çıkması gereken küreselleşme ile kalitenin artık ayrıcı özelliğinin kaybolması, fiyatların oluşan maliyetler sonucu ortaya çıkması gibi kriterler değerlendirildiğinde "maliyet" kavramının ele alınması gereken en önemli başlık olarak çalışmalarda yer alması gerektiği ve işletmelerinde maliyetlerini doğru, hızlı, etkili ve farklılık yaratacak şekilde belirlemesi gerektiği ortaya çıkarmaktadır. Acımasız rekabet koşullarının oluşturduğu baskı unsuru, işletmeleri zorlayan ve nihayetinde fiyatların aşağı çekilmesini sağlayan en önemli sorunu oluşturmaktadır. İşletmeler düşen fiyatlar karşısında kârın aynı düzeyde kalmasını ya da fiyatlar düştügü halde kârın artmasını beklemektedir. Her şartta maliyetlerin indirgenmesi son derece önemli olmaktadır. Bu noktada da maliyetlerin aşağı çekilmesi kadar iyi tespit edilmesi de dikkat edilmesi gereken hassas bir konudur.

Bir ürün yada hizmetin oluşmasında katlanılan tüm unsurlar yada mali fedakarlıklar olarak kısaca tanımlayabileceğimiz maliyetlerin ve maliyet fonksiyonlarının hesaplanmasında kullanılan klasik yöntemlerle elde edilen sonuçların artık işletmeler için yetersiz kaldığı görülmektedir. Karar verici durumunda yer alan üst yöneticilere sunulan bilgiler, özellikle yönetim kararlarını destekleyecek şekilde, faydalı, anlaşılır, güvenilir, tam ve tarafsız olmalı aynı zamanda zamanında sunulmalıdır.

Maliyet fonksiyonlarındaki parametreleri saptamaya yönelmiş klasik yöntem ve teknikler üç grupta incelenmektedir. Bunlardan birincisi, mühendislik yöntemi adı da verilen analitik yöntemde gider unsurları ile iş hacmi veya zaman arasındaki fiziksel bağlantılar belirlenir ve her bir gider unsurunun fiyatlarından faydalanılarak yararlanılarak parasal bağlantılar şekline çevrilir. İkincisi, geçmiş dönemlerde kaydedilmiş tutarlardan hareket 
edilerek önce sabit ve değişken maliyetlerinin belirlenmesi sonrada maliyet fonksiyonunun hesaplanması şeklinde ifade edilen muhasebe yöntemidir. Üçüncüsü ise giderler ile iş hacmi arasında geçmiş dönemlerde oluşan verilerden yararlanılarak bağlantıların matematik ve istatistik yöntemler ile belirlenmesinde oluşan tekniklerdir. Matematiksel ve istatistiksel yöntemlerin diğer tekniklere göre en önemli üstünlüğü bütün giderlere uygulanabilmesi ve doğrudan doğruya toplam maliyet fonksiyonunun saptanmasında kullanılabilmesidir. Matematiksel ve istatistiksel yöntemleri "Grafik Tekniğì, "En Yüksek ve En Düşük Hacimler Tekniği”, "Çifte Ortalama Tekniği” ve "En Küçük Kareler Tekniği” olmak üzere dört ana başlıkta toplayabiliriz (Büyükmirza, 2008:368-390). Bütün klasik yöntemlerin ortaya çıkış nedeni bir önceki yöntemin eksik hususlarının giderilmesi sonucunda ortaya çıkarılmıştır.

$\mathrm{Bu}$ aşamada bilginin çok hızlı bir şekilde değiştiği, klasik tüm yöntemlerin artık yetersiz kaldığı bir dünyada var olmak, değer yaratabilmek ve belki de kâr elde edebilmek için işletmeler yeniliklere açık olmalıdır. Her türlü bilginin olduğu ancak bilgiyi kullananın bir adım öne geçebildiği rekabetçi ve kâr marjlarının daraldı̆̆ı ortamda eldeki verilerin işlenmesi ve değerlendirilmesi önem arz etmektedir. Artık işletmeler yeni teknolojiler ile verileri işlemek ve gelecek hakkında karar vericilerin doğru karar ve stratejiler belirlemesine yardımcı olmak zorundadır. Ancak çok büyük miktarlardaki verinin elle işlenmesi ve analizinin yapılması mümkün değildir. Amaç geçmişteki verileri kullanarak gelecek için tahminlerde bulunmak ise makine öğrenmesi (machinelearning) yöntemleri kullanılacak modeller olarak karşımıza çıkmaktadır. Makine öğrenmesi yöntemleri, geçmişteki veriyi kullanarak yeni veri için en uygun modeli bulmaya çalışır. Çok fazla sayıda makine öğrenmesi yöntemi mevcuttur. Literatürde sıklıkla kullanılan yöntemler ise; Yapay Sinir Ağları (ArtificialNeural Network), Destek Vektör Makineleri (SVM-SupportVector Machine), Karar Ağaçları (DecisionTree), K-En Yakın Komşuluk ( K- NearestNeighbor / $\mathrm{KNN}$ ).

Yapay sinir ağları (YSA), insan beyninin özelliklerinden olan öğrenme yolu ile yeni bilgiler türetebilme, yeni bilgiler oluşturabilme ve keşfedebilme gibi yetenekleri, herhangi bir yardım almadan otomatik olarak gerçekleştirebilmek amacı ile geliştirilen bilgisayar sistemleridir (Öztemel, 2003:29)İnsan beyni rassal sayı üretimini kendi zihninde belli bir sistematik kullanarak gerçekleştirmektedir. Bir insana rassal bir sayı söylemesi istendiğinde söyledi sayılar kendince rassal (tesadüf) iken aslında rassal olarak değil kendi zihnindeki mental hesaplama işlemi sonucunda belli bir sistematik ile üretilmektedir. YSA; insan beyninden esinlenerek, öğrenme sürecinin matematiksel olarak modellenmesi uğraşı sonucu ortaya çıkmıştır. Bu nedenledir ki, bu konu üzerindeki çalışmalar ilk olarak beyni oluşturan biyolojik üniteler olan nöronların modellenmesi ve bilgisayar sistemlerinde uygulanması ile başlamış, daha sonraları bilgisayar sistemlerinin gelişimine de paralel olarak birçok alanda kullanılır hale gelmiştir. YSA'ların öğrenme özelliği en dikkat çekici özelliğidir. YSA genel olarak canlı beyninin yapısını gerçekleştirmeyi hedefler ve aşağıdaki işlemleri gerçekleştirebilir.

- Öğrenme

- İlişkilendirme

- Siniflandirma

- Genelleme
- Tahmin

- Özellik belirleme

- Optimizasyon 
$\mathrm{Bu}$ işlemleri YSA'nın ortak noktası ise bir müdahale yapılmaksızın, elinde bulunan bilgilere göre sonuç üretebilmesidir. YSA öğrenme işlemi sırasında verilen bilgiler ile kendini düzenleyerek daha sonraki girdiler için doğru kararlar verebilme yeteneğine sahiptir. YSA modelleri biyolojik sinir ağlarının çalışmasından esinlenerek ortaya çıkarılmıştır. Canlılarda bulunan sinir sisteminin modellenmesi sayesinde yapay sinir ağları biyolojik sinir sisteminin üstünlüklerine sahip olmuştur. Çalışmamızda artık her alanda kullanılmaya başlanan yeni teknoloji ve programlardan YSA'nın kullanılarak işletmelerin belkide kâr maksimizasyonu sağlamak için dikkatli bir şekilde tahmin etmek ve belirlemek zorunda oldukları maliyetlerin de doğru belirlenmesi için kullanılıp kullanılamayacağına dair bir varsayım üzerinde durulmuştur.

\section{YAPAY SINIR AĞLARI}

İnsan beyni henüz keşfedilememiş ancak keşfetme duygusunun binlerce y1l ötesine dayandığı bir bilinmezdir. Elektronik ve teknolojinin gelişimi ile beraber bu karmaşık düşünce sistemini kullanabilmeyi hedefleyen çalışmalar hız kazanmıştır. Sentetik ağ olarak tanımlanan YSA'ya ait ilk model 1943 yılında bir sinir hekimi olan Warren Mc Culloch ve bir matematikçi olan WalterPitts tarafından Sinir Aktivitesinde Düşüncelere Ait Bir Mantıksal Hesap (A Logical Calculus of IdeasImmanent in Nervous Activity) başlıklı makale ile ortaya çıkarılmıştır. Ardından yapay sinir ağlarındaki bazı problemlerin giderilmesi ile beraber 1980 yılarının sonlarında dünya çapında yaşanan önemli gelişmeler ile birlikte yapay sinir ağları da gelişimine hız katarak devam etmiştir (Irwin, Warwick, \&Hunt, 1995:3). Gelişen yapay sinir ağları yakın gelecekte, sistemlerin özellikle robotların günlük hayatta yaşam kalitesinin artırılmasına yönelik ne denli önemli bir etken olabileceklerine işaret etmektedir.

İnsan beyninde yaklaşık $10^{11}$ sinir hücresinin varlığından bahsedilmekle birlikte, bu sayının bilgisayar ortamında modellenmesi şu an için mümkün görünmemektedir. Fakat karar hızı açısından insan beyni ile henüz yarışamasalar bile, YSA'lar yapısallıkları ve hassas eşleştirmelerin başarı ile gerçekleştirebilmeleri ile gün geçtikçe daha fazla uygulama alanı bulmaktadır.Sinir hücreleri, birbirleri ile ilişki içindedirler. Bu sıkı ilişki, sinirsel işlevin temelini oluşturan bilgi akışını sağlar (Yazıcı ve diğerleri, 2007:66). YSA, biyolojik sinir hücresinin (nöron) yapısını taklit ederek, öğrenmeyi gerçekleştirmektedir.

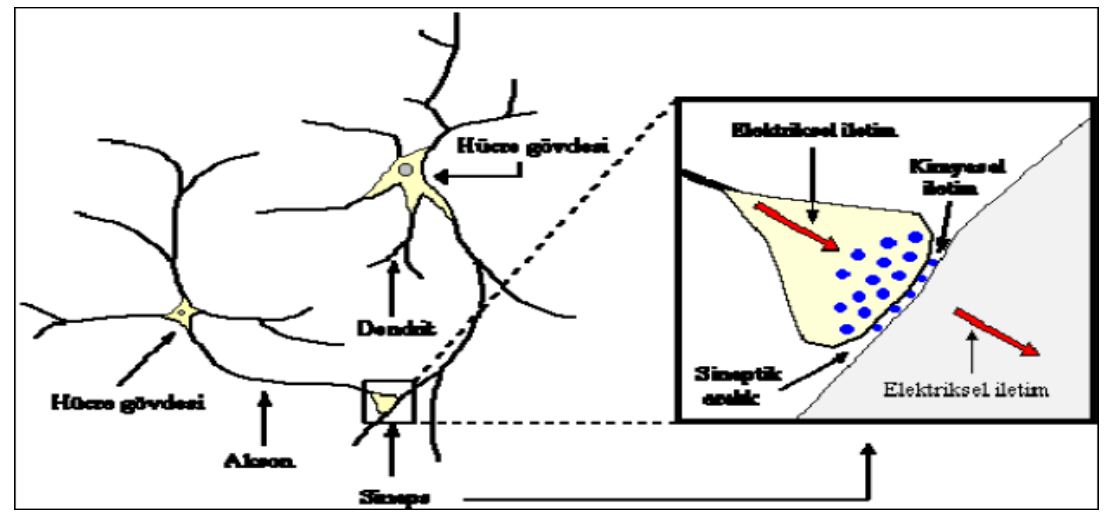

Kaynak: Să̆ıroğlu ve diğerleri, 2003:28

Şekil 2. Biyolojik Nöron Hücre Yapıs1 
Şekil 2'de de görüldüğü gibi nöronlar kendi aralarında bağlantılar kurarak, elektrik devreleri gibi iletişim sağlayıp, beyin fonksiyonlarının ortaya çıkmasını sağlayan ana elemanlardir.

\subsection{Yapay Nöron Yapısı ve Aktivasyon Fonksiyonları}

Biyolojik nöron yapısında yer alan birimlerin yapay nöron yapısındaki karşılıkları Tablo 1'de gösterilmiştir.

Tablo 1: Biyolojik ve Yapay Nöron Yapıları

\begin{tabular}{|l|l|}
\hline (Biyolojik Nöron Yapısı & Yapay Nöron Yapısı \\
\hline Nöron & İşlem Elemanı \\
\hline Dendrit & Toplama Fonksiyonu \\
\hline Hücre Gövdesi & Aktivasyon Fonksiyonu \\
\hline Akson & Çıkış Değeri \\
\hline Sinaps & Ăğılıklar \\
\hline
\end{tabular}

Kaynak: Să̆ıroğlu ve diğerleri, 2003:28

Bir yapay nöron Şekil 3'de görüldüğü gibi, girdiler $\left(u_{i}\right)$, ağırlıklar $\left(w_{i}\right)$, toplama fonksiyonu $(S)$ ve aktivasyon fonksiyonundan $(\Psi)$ oluşmaktadır. Burada girişler, diş kaynaklardan ya da öteki işlem elemanlarından gelen işaretlerdir. Bu işaretler, kaynağına göre güçlü ya da zayıf olabileceğinden ağırlıkları da farklıdır. YSA'da girilen giriş değerlerine, eşitlik 1'de görüldüğü gibi önce toplama fonksiyonları uygulanır ve her bir işlem elemanının çıkış değeri hesaplanır. Burada $\left(u_{i}\right)$, i'inci girişi, $\left(w_{i}\right)$ i'inci ağırlığını ve $\theta$ eşik değerini göstermektedir. Daha sonra bu çıkış değerleri aktivasyon fonksiyonuna (eşitlik 3) yani öğrenme eğrisine uygulanır ve çıkış değeri bulunur. Girdiler elde edilen ham verilerdir ve düzenlenerek ya da ham veri olarak sisteme aktarılabilmektedirler.

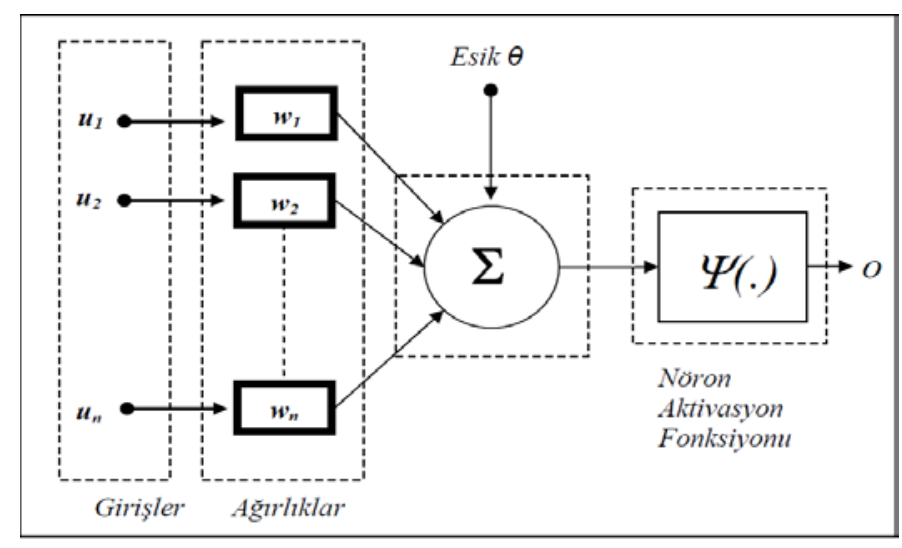

Kaynak: Efe, Kaynak, 2004: 6

Şekil 3. Yapay Nöron Hücresinin Yapısı

Ağırlıklar, nöronlar arasındaki bağlantının gücünü ölçer. Pozitif ağırlık, nöronun sinyal çıkarmasını sağlarken, negatif ağırlık nöronun çıktısını engeller. Birçok sistemde ağırlıklar, bilgisayar programları ile yapılır. Ağırlıkların değiştirilmesi yapay sinir ağlarının öğrenmesidir. 


$$
\begin{array}{ll}
S=w_{1} u_{1}+w_{2} u_{2}+\cdots+w_{n} u_{n}-\theta=\sum_{i=1}^{n} w_{i} u_{i}-\theta & \text { Eşitlik 1 } \\
0=\Psi(S) & \text { Eşitlik 2 }
\end{array}
$$

Aktivasyon fonksiyonları, girdi verileri ve ağırlıklara karşılık, nöronun çıktısını belirleyen matematiksel bir denklemdir. Yapay Sinir Ağlarında kullanılan birçok aktivasyon fonksiyonu bulunmaktadır. Bunlardan iki tanesi Sigmoid Fonksiyon ve Basamak Fonksiyonudur.

Sigmoid fonksiyonu, 3. eşitliği kullanır. Sigmoid fonksiyonu gerçek değerleri alarak $(0,1)$ aralığındaki değerlere dönüştürür.

$$
\begin{array}{ll}
\Psi_{1}(\mathrm{~S})=\frac{1}{1+e^{-S}} & \text { Eşitlik 3 } \\
\Psi_{1}(\mathrm{~S})=\left(\begin{array}{ll}
0, & 0<0.5 \\
1, & 0.5<0
\end{array}\right) & \text { Eşitlik 4 }
\end{array}
$$

Basamak fonksiyonu, 4. eşitliği kullanır, giriş değerlerinin belirli bir eşik değerden büyük ya da küçük olmasına göre 0 ya da 1 değerlerine dönüştürür.

YSA modelinin bazı klasik istatistiksel yöntemlerin genelleştirilmiş hali olduğu görülmüştür. İstatistikte doğrusal olmayan modellerde kullanılan yöntemler ile YSA algoritmaları eğitilerek sonuç üretilebilmektedir. İstatistikte YSA genellikle esnek olarak doğrusal olmayan regresyon analizi veya sınıflandırma modelleri olarak kullanılmaktadırlar. Pek çok YSA algoritmasının parametrik olmayan istatistiksel yöntemlerle yakın ilişkisi vardır. Özellikle değişken uzayı karmaşık ve verinin dağılımı, bilinen istatistiksel dağılımlardan farklıysa YSA bir istatistiksel analiz yöntemi olarak kullanılabilir (Haykin, 1999:14-68).

YSA'da öğrenmek, nöronlar arasındaki ağırlık vektörünün değerini en aza indirgenmesi ile sağlanır. YSA öğrenmesinin en iyi açıklandığı örnek Pavlov’un köpekler üzerineyaptığı deneydir. Köpekler Pavlov'un onlara yiyecek göstermesiyle salya akıtırlar. Öğrenme gerçekleşmiştir. İkinci aşamada kafese zil yerleştirilir. Yiyecek ile zil arasında bağ kurulmaya çalışılır ancak köpekler tepki vermez çünkü gerekli öğrenme süreci yaşanmamıştır. Öğrenme süreci tamamlandıktan sonra zil çaldığında da köpekler yiyeceği görmeseler de salya akıtmaya başlarlar. Görüldüğü üzere zil ile salya arasında bir bağ yokken öğrenme süreci tamamlandıktan sonra davranış değişmektedir. Burada da YSA'da eğitimin amacı, ağagösterilenörnekleriçindoğruçıktılarıüretecekağırlıkdeğerlerini bulmaktır. Ağın doğru ağırlık değerlerine ulaşması örneklerin temsil ettiği olay hakkında genellemeler yapabilme yeteneğine kavuşması demektir. Ağın bu genelleştirme özelliğine kavuşması işlemine "ağın öğrenmesi” denir.

\subsection{Yapay Sinir Ağlarının Avantaj ve Dezavantajları}

Her model, teknik, simülasyon veya programda olduğu gibi YSA'nın da bazı avantaj ve dezavantajları mevcuttur. Ancak fayda ve mahzurlar ortaya konulduğunda büyük veri yığınlarında mevcut yöntemlerin aksine daha etkili, hızlı ve verimli sonuçlar ortaya çıkarmaktadır. Avantajları; 
- Varsayım gerektirmez.

- Eksik veri ile çalışabilir.

- YSA'ların bir ya da birden fazla hücresinin bozulması çıktı üretmesini engellemez. $\mathrm{Bu}$ özellik ağları hata töleransına sahip kılar.

- Veriler doğrusal olmayabilir.

- Öğrenme süreci vardır.

- Genelleme, Sinıflandırma, Kümeleme yapar.

- Çok Sayıda Değişken ve Parametre Kullanır. Hatta modelin öğrenme sürecini en verimli şekilde tamamlayabilmesi için verilerin olabildiğince fazla olması gerekmektedir.

Dezavantajlar1;

- Kara kutu özeliği vardır. YSA bir probleme çözüm ürettiği zaman, bunun neden ve nasıl olduğuna ilişkin bir ipucu vermez. YSA yapısının belirlenmesinde belirli bir kural yoktur.

- Uygun ağ yapısı deneyim ve deneme yanılma yolu ile elde edilmektedir.

- Ağın başarısı, seçilen örnekler ile doğru orantılıdır, ağa olay bütün yönleri ile gösterilemezse ağ yanlış çıktılar üretebilir.

- Aynı katman ve nöron sayısını da kullansanız program her çalıştığında farklı sonuçlara ulaşırsınız.

\subsection{Yapay Sinir Ağlarının Öğrenme Stratejileri}

YSA'da diğer örneklerden öğrenen sistemlerde olduğu gibi değişik öğrenme stratejileri kullanılmaktadır. Öğrenme sürecini gerçekleştiren süreç ve öğrenme algoritması uygulanan stratejilere bağlı olarak değişmektedir. Genel olarak üç öğrenme strateji uygulanmaktadir.

\subsubsection{Danışmanlı Öğrenme (Supervised Learning) Stratejisi}

Bu stratejide, öğrenen sisteme bir danışman yardımcı olmaktadır. Danışman sisteme öğrenilmesi istenen olayla ilgili örnekleri veri seti olarak vermektedir. Kısaca, her örnek için hem girdiler hem de o girdiler karşılığında oluşturulması gereken çıktılar sisteme gösterilir. Sistemin görevi, danışmanın belirlediği yol haritasına göre olayın girdileri ile çıktıları arasındaki ilişkileri öğrenmektir (Öztemel, 2003: 25).

Elde edilen sonuçların çıktı değerleri (ölçüm değerleri) ile karşılaştırılması arasındaki farklar hata olarak gözlenir. Bu hataların kareleri toplamının en küçüklenmesine yönelecek biçimde YSA yapısındaki sinirler arası bağlantı (ağırlık) değerleri hesaplanarak en küçük hata ile çıktılara yaklaşılır. Burada girdilerden çıtıllara doğru bir ileriye akış ve hat teriminin istenilen sınırlar içinde olmaması durumunda da çıktılardan girdilere doğru bir geri akış (geri besleme) olacaktır. Ancak bu ileriye gidiş ve gelişlerde girdi değişkenleri asla değerlerinin değiştirmeyecek ama hep çıktı değişkenleri değerlerini ölçümlere yaklaşacak biçimde değiştirecektir. 
$\mathrm{Bu}$ ileri ve geri gidiş ve gelişler bağıl hata teriminin istenen değerden, örneğin seçilecek \%5 ya da \%10'dan küçük kalması durumunda, YSA işleyişine son verecektir. Böylelikle YSA bundan sonra gelecek girdi verilerinden çıktıları hesaplayarak öngörüde bulunmakta kullanabilecektir. Bu işlemde öğrenme, hataların kareleri toplamının en az indirgenmesi ile yapılmaktadır (Şen, 2004: 99).

\subsubsection{Danışmansız Öğrenme (Unsupervised Learning) Stratejisi}

$\mathrm{Bu}$ stratejide sistemin öğrenmesine yardımcı olan herhangi bir danışman yoktur. Sisteme yalnızca girdi değerleri gösterilmekte örneklerdeki parametreler arasındaki ilişkileri sistemin kendi kendisine öğrenmesi beklenmektedir. Yalnız sistemin öğrenmesi bittikten sonra çıktıların ne anlama geldiğini gösteren etiketlendirmenin kullanıcı tarafindan yapılması gerekmektedir (Öztemel, 2003: 25).

Hiç çıkış bilgisi olmayan bu stratejide arzu edilen çıkışlar ağa hiç verilmediğinden hata dikkate alınmaz. Verilen giriş bilgileri, YSA tarafından işlenerek ayrıştırmalar yapılır. Ayrıştırma yapılmasında hedef mümkün olduğu kadar farklı sınıfların belirlenmesidir. Bu yüzden bağlantı ağırlıkları yalnızca giriş verilerine bağlı olarak değişir. Ayrıştırma ölçütleri daha önceden bilinmiyor olabilir. Bu gibi durumlarda ăg kendi sinıflandırma kuralının geliştirmelidir. Ancak bu tür öğrenme sınırlı sayıda YSA modelinde uygulanabilmektedir (Şen, 2004, 100).

\subsubsection{Takviyeli Öğrenme (Reinforcement Learning) Stratejisi}

Danışmanlı öğrenme stratejisinde olduğu gibi bu stratejide de sisteme bir danışman yardımcı olur. Fakat danışman çıktı setini sisteme göstermek yerine sistemin kendisine gösterilen girdilere karşılıkçıktısı üretmesini bekler ve üretilen çıktının doğru ve yanlış olduğunu gösteren bir sinyal üretir. Sistem danışmandan gelen bu sinyali dikkate alarak öğrenme sürecini sürdürür (Öztemel, 2003: 25).

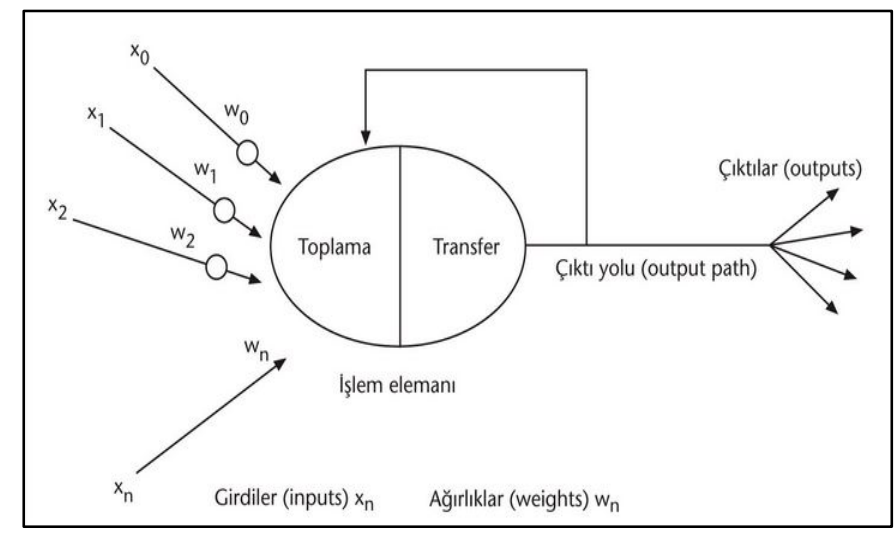

Şekil 4. YSA Öğrenme Süreci

\subsection{Yapılarına Göre Yapay Sinir Ağları}

Yapay sinir ağları içerdiği nöronların birbirine bağlanış şekline göre ileri ve geri beslemeli olarak ikiye ayrılır. İleri Beslemeli Ağlar: İleri beslemeli ağlarda nöronlar girişten çıkışa doğru düzenli katmanlar şeklindedir. Aşağıdaki şekilde nöronlara giden eğimin (bias) 
dikkate alınmadığı ve eğim ile söz konusu doğrunun konumunun değişmesi sağlanmaya çalışıldığı İleri Doğru Beslemeli bir YSA örnek uygulaması görülmektedir.

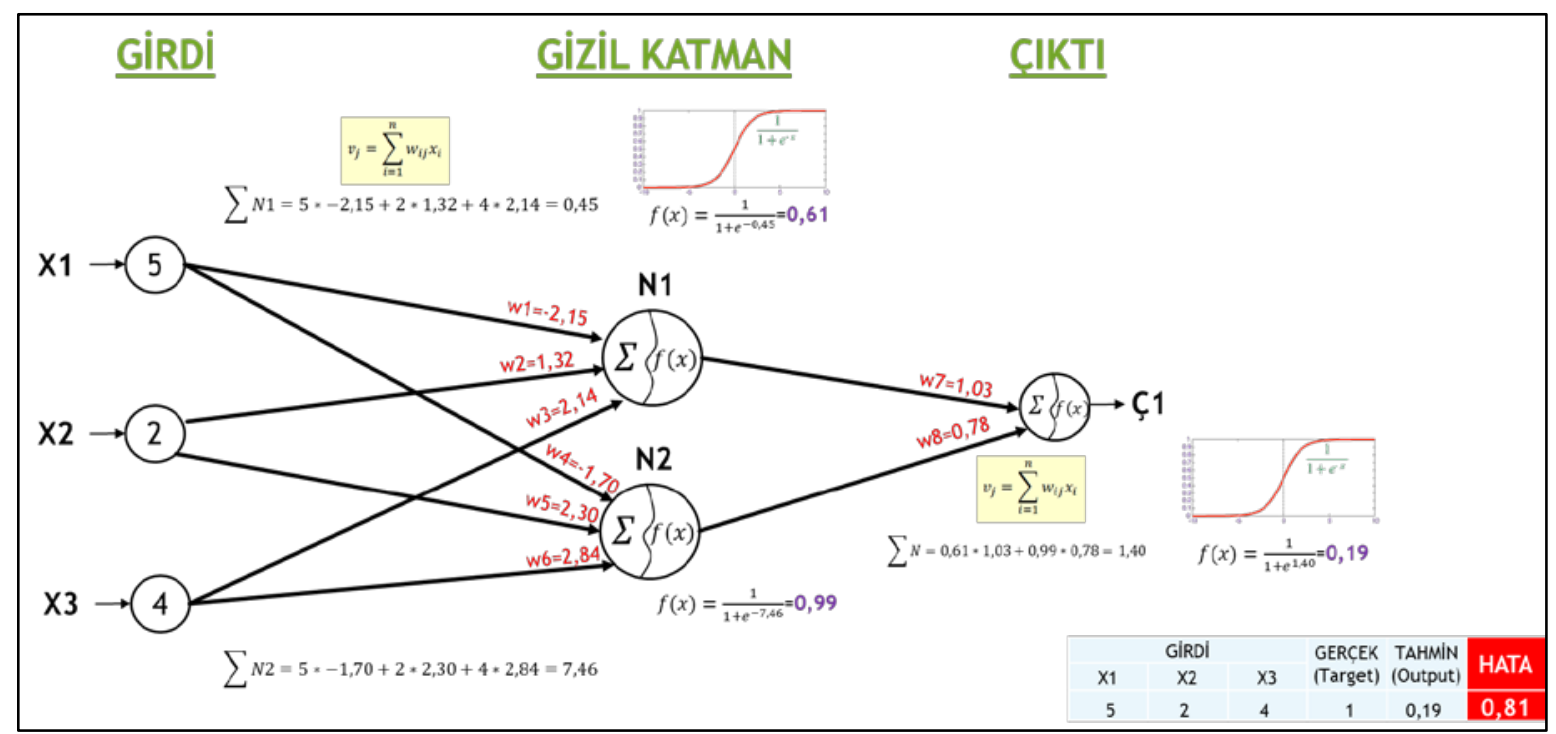

Şekil 5. İleri Doğru Beslemeli YSA Örnek Uygulaması.

Geri Beslemeli Yapay Sinir Ağları: Geri beslemeli yapay sinir ağlarında ileri beslemeli olanların aksine bir hücrenin çıktısı sadece kendinden sonra gelen hücrenin katmanına girdi olarak verilmez. Kendinden önceki katmanda veya kendi katmanında bulunan herhangi bir hücreye de girdi olarak bağlanabilir. Bu yapısı ile geri beslemeli yapay sinir ağları doğrusal olmayan dinamik bir davranış göstermektedir.

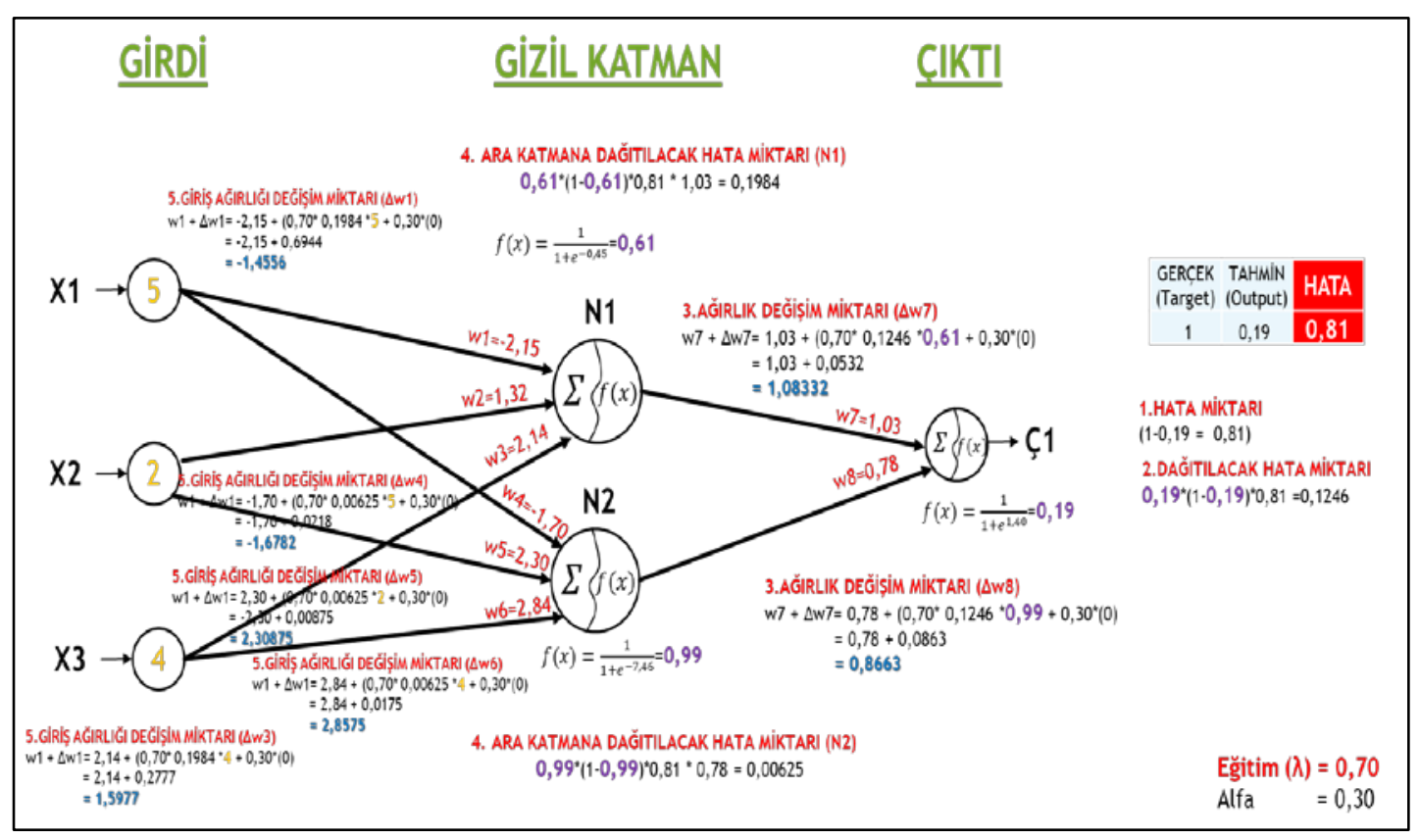

Şekil 6. İleri Doğru Beslemeli YSA Örnek Uygulaması. 


\subsection{Yapay Sinir Ăglarında Kullanılan Öğrenme Modelleri}

YSA'da, işlemci elemanların bağlanması sonucu oluşan geometrik düzen, sahip oldukları toplama ve aktivasyon fonksiyonları, kullanılan öğrenme yöntemi ve öğrenme kuralı ağın modelini belirlemektedir. YSA'nın daha hızlı ve daha başarılı sonuçlar üretmesini sağlamaktadır. Bir problemin çözümü için uygulanacak olan YSA modeli öncelikle problemin türüne bağlı olmaktadır. Hangi ağ modelinin hangi problemin çözümü için daha uygun olduğunun bilinmesi oldukça önemlidir (Baş, 2006:38). Uygulamada en fazla kullanılan modeller ise şöyledir;
a. Alg1layıc1lar,
b. Çok Katmanlı Algılayıcılar
c. Kendi Kendini Düzenleyen Model
d. Adaptif Rezonans Teorisi Modelleri

e. Hopfield Ağları

f. Boltzman Makinesi

g. Radyal Temelli Ağlar

h. Doğrusal Vektör Kuantizasyon Modeli

\section{LITERATÜR TARAMASI}

YSA; uzay sektörü, sigortacılık, sağlık, robotik, telekomünikasyon ve güvenlik alanlarında önemli gelişmeler gösterdiği gibi akademik dünyada da ilgi gören bir konu olmaktadır. YSA ile ilgili olarak yapılan çalışmalar ise şöyle sıralanabilir.

- 2018 yılında yapılan "Yapay Sinir Ağları Analizi İle İmalat Süreçlerinin İyileştirilmesi”,

- 2018 yılında yapılan “Öğrenci Başarılarının Yapay Sinir Ağları ile Kestirilmesi”,

- 2017 yılında yapılan "Yapay Sinir Ağı İle Hava Sıcaklığı Tahmini”,

-2014 yılında yapılan "Yapay Sinir Ağı İle Rüzgâr Hızının Tahmini”,

- 2018 yılında yapılan "Yapay Sinir Ağları İle Otomobil Satış Tahmini”,

- 2011 yılında yapılan "Yapay Sinir Ağları Ve Türkiye Elektrik Tüketimi Tahmin Modeli”,

- 2012 yılında yapılan "Yapay Sinir Ağları Kullanılarak Konaklama İşletmelerinde Doluluk Oranı Tahmini”,

- 2015 yılında yapılan “Talep Tahmininin Yapay Sinir Ağlarıyla Modellenmesi: Yerli Otomobil Örneği” konulu çalışmalar örnek olarak gösterilebilir.

Söz konusu tüm çalışmalarda; veriler YSA ile değerlendirilmiş ve geleceğe yönelik olarak yapılan tahminler klasik yöntemler ile karşılaştırılmıştır.

\section{UYGULAMA}

$\mathrm{Bu}$ çalışmada, maliyet fonksiyonlarının YSA ile tahmin edilmesi amacına yönelik olarak; $\mathrm{m}^{2}$ başına düşen bir evin maliyetinin hesaplanması amaçlanmaktadır. Maliyetler klasik maliyet fonksiyonu tahmin yöntemleri ile belirlenmeye çalışılmış daha sonra eldeki veriler danışmanlı öğrenme özelliklerinde yapılandırılan Yapay Sinir A $\breve{g}$ 'na veri olarak girilmiştir. Yapılan öğrenme ve test etme işlemlerinin ardından maliyet tahminleri yaptırılmıştır. Elde edilen sonuçlara, maliyet tahmini için oluşturulacak Yapay Sinir A ve elde edilecek verilerin kullanılabilirliği değerlendirilmiş, bu konuda sağlanan sonuçlara göre, maliyet değerlerinin doğruluğa yakınlığı, diğer yöntemlerle olan performans karşılaştırtmaları ve bu yöntemin kullanımı ile sağlanacak maliyet ve zaman tasarrufu yorumlanmıştır. 


\subsection{Yöntem ve Varsayımlar}

Yapay sinir ağı ile maliyet fonksiyonunu belirlemeye çalışırken söz konusu $\mathrm{m}^{2}$ başına bir evin toplam maliyet fonksiyonu öncelikle klasik yöntemlerden olan en küçük kareler yöntemi ile belirlenmeye çalışılmış ve istatistiki metotlar kullanılarak sonuçlar analiz edilmiştir. Daha sonra YSA ile model oluşturularak maliyet fonksiyonu hesaplanmaya çalışılmıştır.

\subsection{Veri}

Metre kare başına gayrimenkul maliyetini temsil edecek bir maliyet fonksiyonunu belirlemek için 2013 ve 2014 yılları arasında satılan 414 gayrimenkulün maliyet verileri kullanılmıştır. Söz konusu gayrimenkul maliyetine etki ettiği düşünülen 6 bağımsız değişken bulunmaktadır. Bunlar sırasıyla; işlem tarihi (ay), gayrimenkulün yaşı (yıl), sosyal alanlara yakınlık derecesi (m), çevresinde bulunan marketlerin sayısı, enlem, boylam derecesi olarak belirlenmiştir. Modelde kullanılan veriler makine öğrenmesi modelleri için veri sağlayan https://archive.ics.uci.edu/ml/index.phpüzerinden alınmıştır. Veriler kullanılarak bağımsız değişkenlerin gayrimenkul maliyeti üzerindeki etkisini ortaya koyacak bir maliyet fonksiyonu tespit edilerek, satılması düşülen bir gayrimenkulün maliyetinin tahmin edilmesi amaçlanmaktadır.

\subsection{Analiz}

\subsubsection{En Küçük Kareler Tekniği}

\section{Descriptive Statistics}

\begin{tabular}{|l|r|r|r|}
\hline & Mean & Std. Deviation & $\mathrm{N}$ \\
\hline Y & 37,6906 & 13,77641 & 339 \\
$\mathrm{X} 1$ & 6,4749 & 3,11540 & 339 \\
$\mathrm{X} 2$ & 17,6463 & 11,58155 & 339 \\
$\mathrm{X} 3$ & 1108,6108 & 1256,44283 & 339 \\
$\mathrm{X} 4$ & 4,0206 & 2,98460 & 339 \\
$\mathrm{X} 5$ & 24,9688 &, 01235 & 339 \\
$\mathrm{X} 6$ & 121,5331 &, 01549 & 339 \\
\hline
\end{tabular}




\section{Correlations}

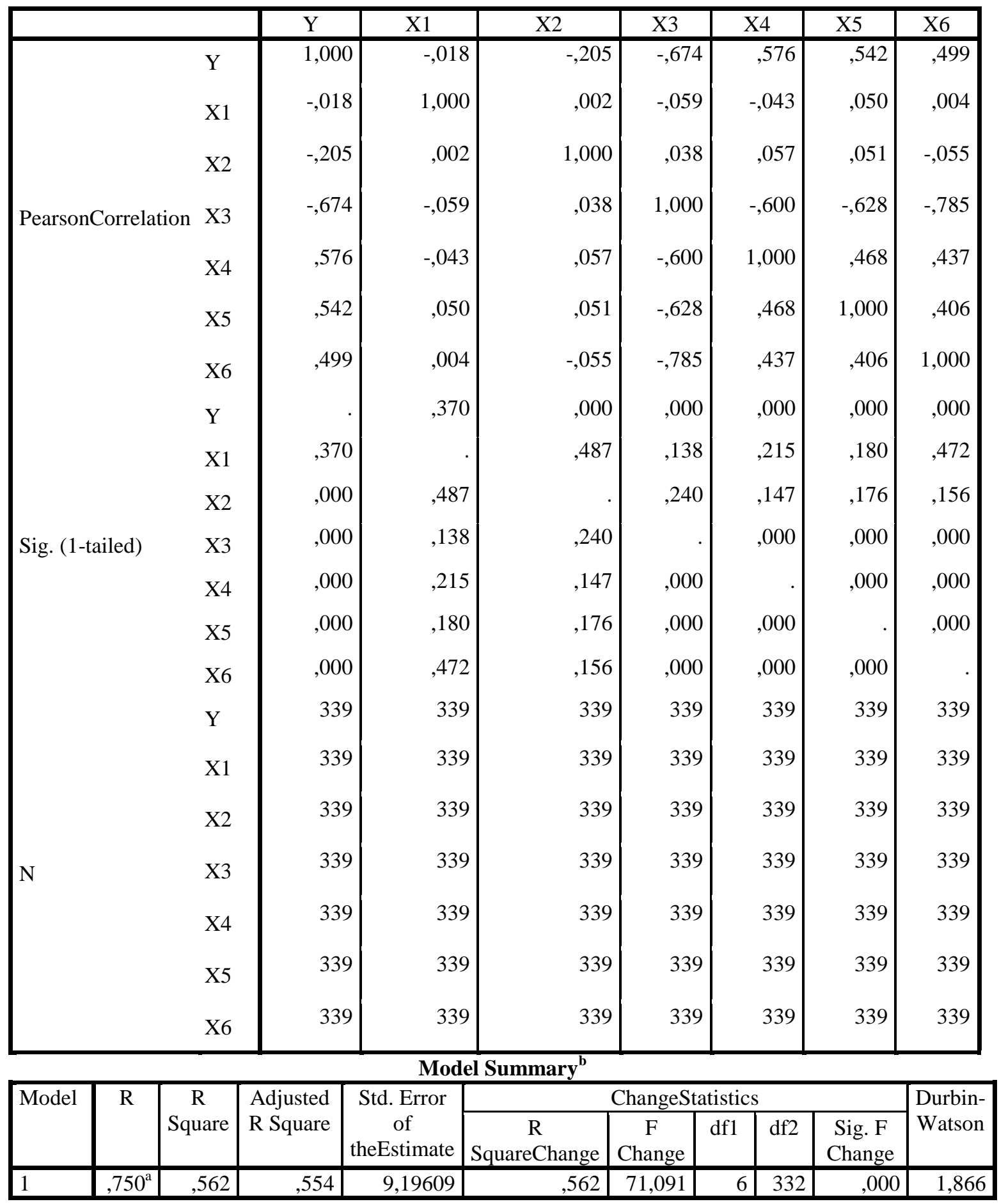

a. Predictors: (Constant), X6, X1, X2, X5, X4, X3

b. DependentVariable: Y 
The Journal of Accounting and Finance- August 2019 Special Issue 329-344

\begin{tabular}{|r|r|r|r|r|r|r|}
\hline \multicolumn{2}{|c|}{ Model } & \multicolumn{1}{c|}{ NNOVA $^{\text {a }}$} \\
& & $\begin{array}{c}\text { Sum of } \\
\text { Squares }\end{array}$ & df & MeanSquare & F & Sig. \\
\hline \multirow{2}{*}{1} & Regression & 36072,240 & 6 & 6012,040 & 71,091 &, $000^{\mathrm{b}}$ \\
& Residual & 28076,630 & 332 & 84,568 & & \\
& Total & 64148,870 & 338 & & & \\
\hline
\end{tabular}

a. DependentVariable: $\mathrm{Y}$

b. Predictors: (Constant), X6, X1, X2, X5, X4, X3

Coefficients $^{\mathrm{a}}$

\begin{tabular}{|c|c|c|c|c|c|c|c|c|c|c|}
\hline \multirow[t]{2}{*}{ Model } & \multicolumn{2}{|c|}{$\begin{array}{l}\text { Unstandardized } \\
\text { Coefficients }\end{array}$} & \multirow{2}{*}{$\begin{array}{c}\text { Standardized } \\
\text { Coefficients } \\
\text { Beta }\end{array}$} & \multirow[t]{2}{*}{$\mathrm{t}$} & \multirow[t]{2}{*}{ Sig. } & \multicolumn{3}{|c|}{ Correlations } & \multicolumn{2}{|c|}{ CollinearityStatistics } \\
\hline & B & Std. Error & & & & $\begin{array}{l}\text { Zero- } \\
\text { order }\end{array}$ & Partial & Part & Tolerance & VIF \\
\hline (Constant) & $-1538,004$ & 6826,529 & &,- 225 & 822 & & & & & \\
\hline $\mathrm{X} 1$ &,- 179 & 162 &,- 040 & $-1,101$ & 272 &,- 018 &,- 060 & $040^{-}$ & 981 & 1,020 \\
\hline $\mathrm{X} 2$ &,- 255 & ,044 &,- 214 & $-5,838$ & 000 &,- 205 &,- 305 & - 212 & 981 & 1,019 \\
\hline $1 \mathrm{X} 3$ &,- 005 & 001 &,- 423 & $-5,622$ & 000 &,- 674 &,- 295 & , 204 & 233 & 4,287 \\
\hline $\mathrm{X} 4$ & 1,210 & 214 & 262 & 5,655 & ,000 & ,576 & 296 & 205 & 613 & 1,631 \\
\hline X5 & 200,984 & 53,543 & 180 & 3,754 & 000 & ,542 & 202 & 136 & ,572 & 1,749 \\
\hline X6 & $-28,278$ & 53,248 &,- 032 &,- 531 & ,596 & 499 &,- 029 & , 019 & 368 & 2,720 \\
\hline
\end{tabular}

a. Dependent Variable: Y

\subsubsection{Yapay Sinir Ağları Modeli}

YSA modeli MS Excel dâhil olmak üzere, SPSS Clementine, MATLAB gibi değişik programlarda kullanılarak sonuca ulaşılmaya çalışılabilir. Çalışmada MATLAB programı kullanılmıştır. Tek katmanlı olarak tasarlanan çalışmada veri setindeki verilerden 60 tanesini manuel olarak test seti olarak ayrılmıştır. YSA'nın çalışma mantığında program öncelikle verilerden kendisine bir eğitim seti oluşturarak veriler arasındaki ilişkiyi öğrenmeye çalışmaktadır. Eğitim setinden elde edilen öğrenme sürecinden sonra büyük veri yığınları arasından tahminler yapıp kendi test verisi ile de bunu test ederek bize sunmaktadır. Buna rağmen 60 veriyi programa dâhil etmeyerek kendi test verimizi de çıkan sonuçlarla değerlendirerek sonuçların güvenirliliği açısından bir bulguya ulaşmaya çalışılmıştır. MATLAB programında dâhil edilen veriler önce tek katmanlı 3 nöronlu bir yap1 ile değerlendirilmiş (Şekil 7.), \%82'lik bir güven derecesine ulaşmıştır. Aynı veriler tek katmanlı 8 nöronlu bir yapı ile değerlendirilmiş (Şekil 8.), \%85'lik bir güven derecesine ulaşmıştır. Nöron sayısının artması güvenirliliği artırıp artırmadığının test edilmesi maksadıyla veriler son kez tek katmanlı 7 nöronlu bir yapı ile değerlendirilmiş (Şekil 8.) ve \%87’lik bir güven derecesine ulaşmıştır. $\mathrm{Bu}$ da göstermektedir ki; nöron sayılarının artması güvenirliliği artıracak kesin bir olgu değildir. YSA'nın belki de en fazla eleştirilen dezavantajlarından birisi de bu noktadır. Aynı veriler, aynı program her çalıştığında farklı sonuçlara 
ulaşmaktadır. Ancak burada da bilinmesi gereken YSA'nın bu eleştirilen özelliğinin de yine farklı bir yapay zekâ uygulaması ile aşılmaya çalışıldığıdır.

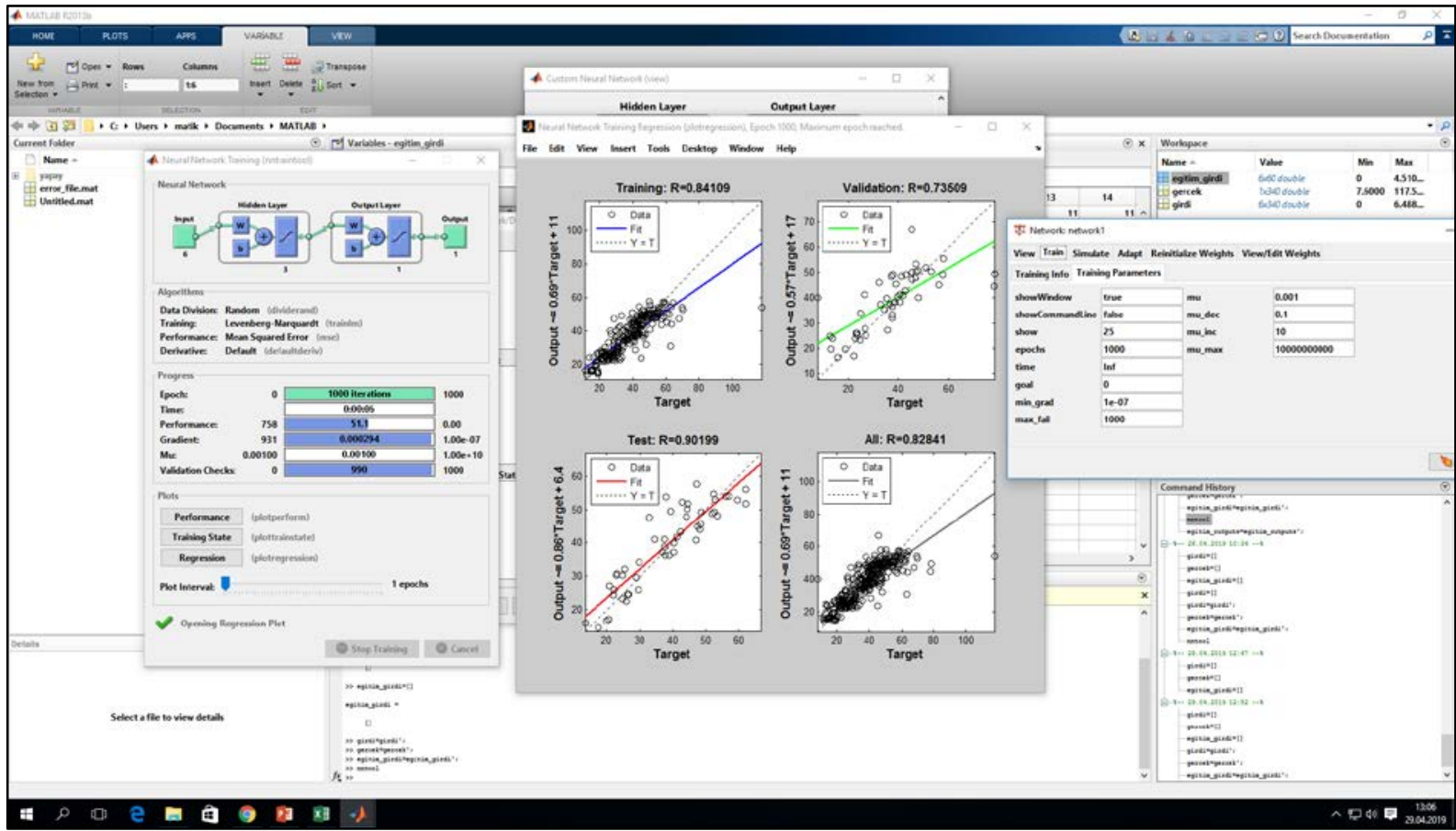

Şekil 7. Tek Katmanlı 3 Nöronlu YSA Modeli

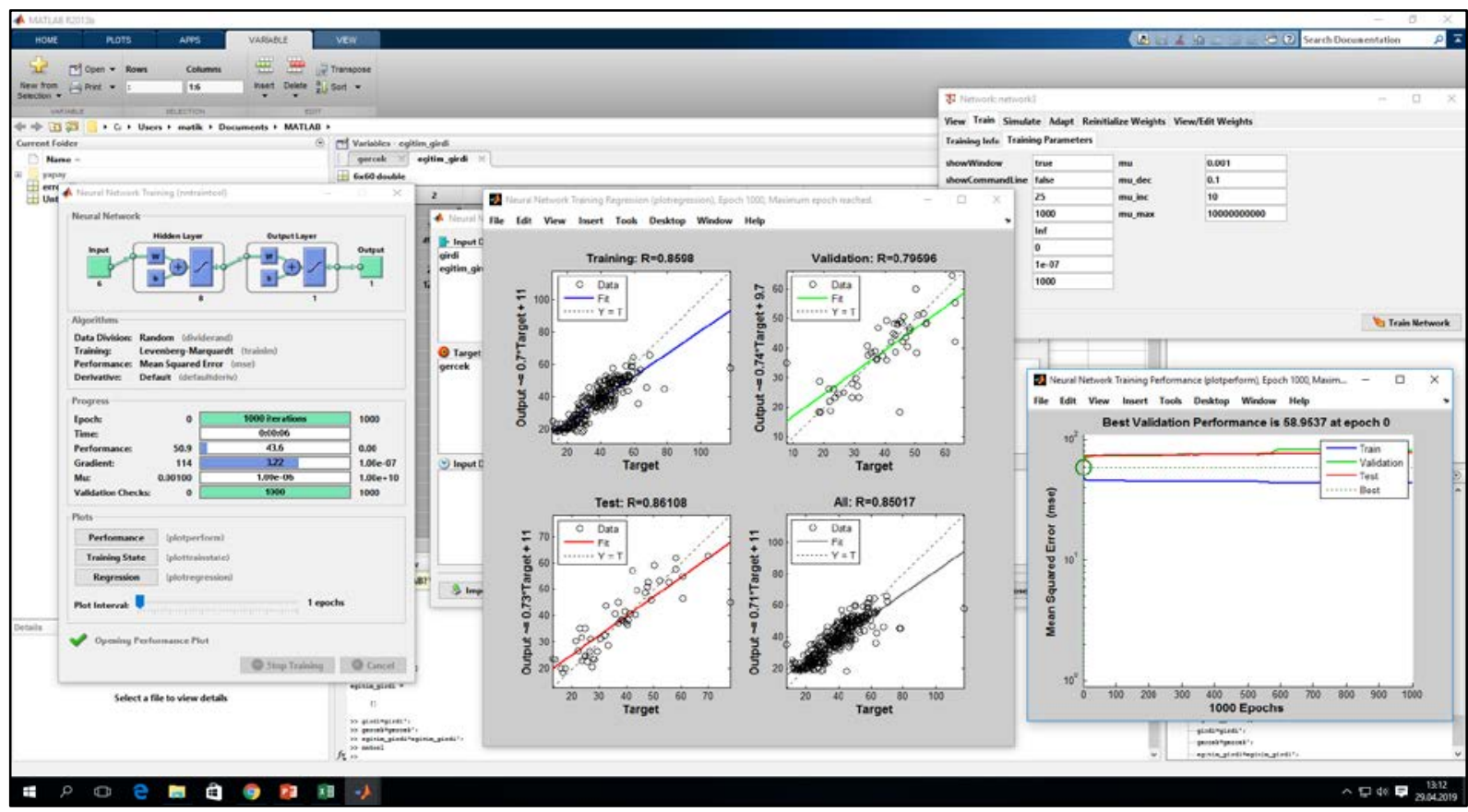

Şekil 8. Tek Katmanlı 8 Nöronlu YSA Modeli 


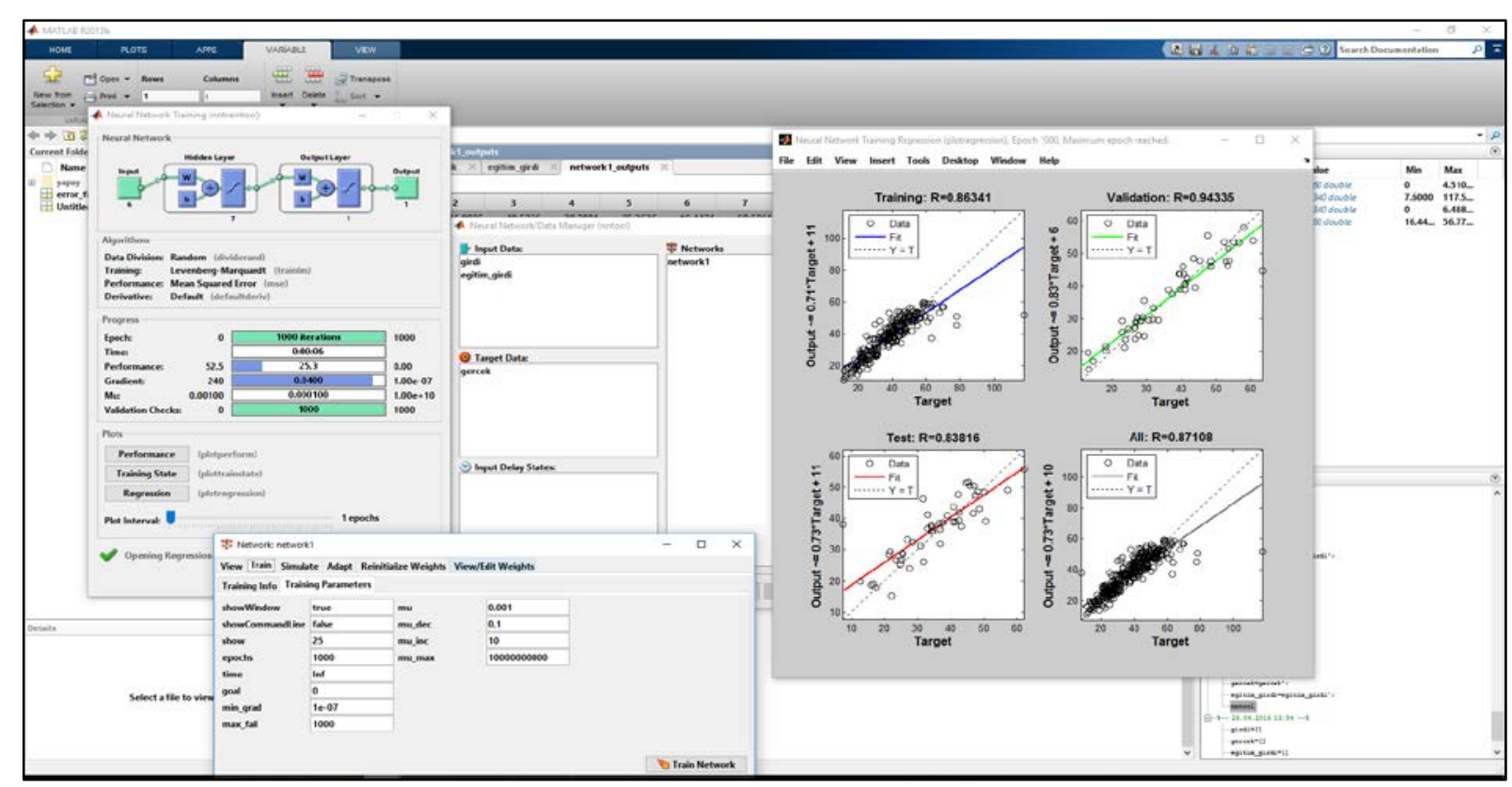

Şekil 9. Tek Katmanlı 7 Nöronlu YSA Modeli

Yapılan tek katmanlı 7 nöronlu YSA modelinde elde edilen veriler kullanılarak önce manuel olarak ayrilan test verileri ile test edilmiş daha sonra da Ek Küçük Kareler Tekniği kullanılarak oluşturulan sonuçlar ile karşılaştırılmıştır. YSA için farklı modeller oluşturularak eğitim ve test verileri için en küçük ortalama hata karesi (meansquareerror-MSE) değerlerine sahip modeller, en iyi modeller olarak seçilmiş ve bu modeller yardımıyla 10 adet test verisi için tahminler gerçekleştirilmiştir. Her iki yöntem yardımıyla elde edilen tahmin sonuçları MSE performans kıstası yardımıyla karşılaştırılmıştır. Her iki performans ölçütü içinde yapay sinir ağı modelleri klasik maliyet fonksiyonu belirleme yöntemlerinden daha iyi tahmin performansı sergilemişlerdir.

\section{SONUÇ}

Maliyet fonksiyonlarının belirlenmesi, işletmelerin stratejik planlarına, karar verme süreçlerine, bütçeleri arasındaki bağlantıyı güçlendirmeye ve harcamaların önceliklendirilmesi sürecine yardımcı olmayı amaçlamaktadır. Maliyetlerimizi iyi ölçmeli ve tahmin etmeliyiz. Geleceği tahmin edemezseniz geleceği yönetemezsiniz. Günümüzün rekabetçi piyasa ortamında işletmelerin fark yaratabilmeleri rakiplerinden her aşamada bir adım önde olmaları ile mümkün olabilmektedir. Teknolojinin bireylere dolayısı ile işletmelere sunmuş olduğu firsatların sınırı yoktur. Bu aşamada işletmeler fark yaratabilmek için eldeki bilgiyi, sunulan firsatlar çerçevesinde değerlendirebilmeli ve kendi lehlerine avantaj sağlamalıdırlar. Sadece yarım yüzyıllık bir geçmişi olan bilgisayarlar yaşantımızın her alanına girmiş durumdadır. Artık salt okur-yazarlığın dışında bilgisayar okur-yazarlık oranları da önemli rakamlara ulaşmıştır. Teknoloji sektöründeki çalışmalar, herhangi bir matematiksel yöntem ile sonucu ifade edilemeyen problemleri insan zekâsının bilgisayarlar üzerine bir tür izdüşümü yardımı ile çözmeyi hedeflemektedir. Bilgisayarlara bu gibi özellikleri kazandırma çalışmaları, makine öğrenmesi, yapay zeka, yapay sinir ağları, big data gibi günümüzün popüler kavramlarını geliştirmiştir. 
İşletmeler maliyet yönetiminin ve geleceğe yönelik tahmin doğruluğunun aynı zamanda rekabet üstünlüğü getirdiği ve işletmelerine bir "değer" kattı̆g olgusunu iyi anlamalıdırlar. Klasik yöntemler sadece var olanı nasıl daha iyi yapabileceğimize dair kanıtlar sunarken, yapay sinir ağları gibi yöntemleri kullanmak olmayanı keşfetmek ve geleceğe yönelik fark yaratmakla ilgili olacaktır. Çalışmamızda literatürde yer alan maliyet düşürme ve maliyet azaltımı (costcutting), maliyet iyileştirme, maliyet değiştirme kavramları üzerinde durulmamış sadece geleceğe yönelik maliyet tahminleri üzerine çalışılmıştır.

YSA, insan beyninin çalışma mekanizmasını taklit ederek beynin öğrenme, hatırlama genelleme yapma yolu ile yeni bilgiler türetebilme gibi temel işlevlerini gerçekleştirmek üzere geliştirilen mantıksal yazılımlardır. Bu çalışmada, yapay sinir ağları ve maliyet fonksiyonu belirlemek için kullanılan klasik yöntemler kullanılarak $\mathrm{m}^{2}$ başına bir evin toplam maliyet fonksiyonu tahmin edilmiştir. Her iki performans ölçütü içinde yapay sinir ağı modelleri klasik maliyet fonksiyonu belirleme yöntemlerinden daha iyi tahmin performans1 sergilemişlerdir. Sonuç olarak; YSA ile elde edilen modelin daha doğru ve güvenilir olduğu tespit edilmiş ve etkinlik açısından değerlendirildiğinde YSA ile maliyet model oluşturmanın zaman ve maliyet tasarrufu açısından daha uygun olduğu yargısına varılmıştır.

\section{KAYNAKLAR}

Baş, N.(2006), Yapay Sinir Ağları Yaklaşımı ve Bir Uygulama, Yayımlanmamış Yüksek Lisans Tezi, Mimar Sinan Güzel Sanatlar Üniv. Fen Bilimleri Enstitüsü, İstanbul.

Büyükmirza, K. (2008), Maliyet ve Yönetim Muhasebesi, Gazi Kitabevi, 12.Bask1.

Carson II, John S.(2003), “Introduction to Modeling and Simulation”, Proceedings of The 2003 Winter Simulation Conference.

Efe, Ö., Kaynak, O. (2004), Yapay Sinir Ağları ve Uygulamalar, Boğaziçi Üniversitesi.

Haykin S.,(1999), Learning Processes, Single-Layer Perceptrons, Multilayer Perceptrons, Neural Networks A Comprehensive Foundation. 2nd edition USA, PrenticeHall International Inc.

Irwin, G. W.-Warwick, K.- Hunt, K. J. (1995),Neural Network Applications in Control. United Kingdom: The Instution of Electrical Engineers.

Öztemel E. (2003), “Yapay Sinir Ağları”, Papatya Yayıncılık.

Sağıroğlu, Ş.- Beşdok, E.- Erler M. (2003), Mühendislikte Yapay Zeka Uygulamaları, Yapay Sinir Ağları, Ufuk Yayınları.

Şen, Z. (2004), Yapay Sinir Ağları İlkeleri, İstanbul: Su Vakfı Yayınları.

Yazıc1, A.C.-Ögüş, E.- Ankaralı, S.- Canan, S.- Ankaralı, H.- Akkuş, Z. (2007), Yapay Sinir Ağlarına Genel Bakış, Türkiye Klinikleri Med. Sci.

https://archive.ics.uci.edu/ml/index.php 